\title{
Distributed Ledger Technologies and Social Machines: How to "Smartify" the Economy with Blockchain-based Digital Extension Services?
}

\author{
Gregory Sandstrom
}

\author{
"The future masters of technology will have to be light-hearted and \\ intelligent. The machine easily masters the grim and the dumb. "
}

Marshall McLuhan (1969)

\begin{abstract}
This paper examines the broad impact of digitalization on economic development. More specifically, it addresses the computer science-derived notion of "social machines", along with the invention of distributed ledger technologies (DLTs) (or blockchain), as potential signposts on the pathway to "smart(er) digital economies". The paper investigates blockchain-based ecosystems as examples of social machines that assist in economic "smartification" and development. It looks at distributed ledger-based communities (DLCs) that provide examples of functioning social machines for a variety of business and personal network communications purposes. It then analyses the scaleup of DLT-based social machines by comparison with "extension services", largely in education and agriculture, which are currently undergoing processes of digitalization. Overall, this conceptual study examines the general horizons and potential impact of blockchain and social machines on the provision of online products and services, across a range of sectors and industries. The paper offers interpretative assistance to managers, entrepreneurs, technology experts, and academics with lingering questions about blockchain in and for business and economic development.
\end{abstract}

\section{Introduction}

What are now called "social machines" have been around for decades as part of a computer-driven wave of digitalization that has taken over developed societies around the world, including but not limited to the invention of the Internet. People and machines are becoming increasingly integrated through computing power, data processing and storage, information management, and Artificial Intelligence (AI), which are all included in the study of "web science" (Shadbolt \& Berners-Lee, 2008, Hall et al. 2016). Economic development now hinges significantly on digitalization and the digital economy, while early mover high tech companies can develop and use advanced technologies to gain strategic advantages over competitors, potentially for years to come.

Berners-Lee and Fischetti coined the term "social machine" in 1999. It joined a language constellation with "social computing" and "cyber-physical systems" to help imagine the future of web-connected societies, or what Wellman (2001) called "networked individualism". The Internet and world wide web, from Web 1.0, to Web 2.0, and the "semantic web" (Hendler \& Berners-Lee, 2010), look set to combine with a new distributed ledger technology (DLT), sometimes known as "blockchain", which was invented at the same time as Bitcoin. Bitcoin itself was invented, coded, and released into the wild in 2009 as "a peer-to-peer electronic cash system with no central mint or trusted third party" (Nakamoto, 2008). 


\section{Distributed Ledger Technologies and Social Machines: How to "Smartify" the Economy with Blockchain-based Digital Extension Services? Gregory Sandstrom}

The trend of using social machines more widely in the electronic-information era coincides with the push in recent decades towards digitalization, and more recently towards the so-called "smartification" (promoting smarter cities, smarter economies, smarter devices). One way to consider it is that " $[\mathrm{s}]$ martification refers to the digital refinement of an existing product by embedding digital technologies and smart services" (Schuh et al., 2019). These processes of smartification thus both require improving technology design "intelligently", in a way that includes strategic planning for niche market acquisition, along with broader economic development. Schuh et al. correspondingly acknowledge that, "[t]he designation 'smart' is common to describe a product that is extended with digital functions and customer-oriented services" (2019).

Considering the relatively new terminology, this paper explores the potential for smartification in the context of entrepreneurial and business activities that are arising from the use of DLTs to create "ledger communities" (LCs). As DLTs make use of the Internet, information services, big data, encryption, and "smart devices" (which may hold digital wallets), some have even suggested this powerful mixture of technological capabilities has brought us now to the brink of a "blockchain revolution" (Tapscotts, 2016, 2016a \& 2017, 2017a). This language contrasts with speaking less abruptly about "the rise of social machines" (Shadbolt et al., 2016), and more gradually about how their development is transforming the human/digital ecosystem globally.

Practically no studies have investigated the interface or potential synergy between DLTs and social machines, and none considering smartification trends. Thus, the paper addresses an existing gap in the literature between DLTs and social machines, with only one paper found that combined the terms "blockchain" and "social machines", and not in a significant way. The starting premise of the study is that such synergy would be valuable to consider. It goes further than the currently available literature by using "scalability" as a comparable point of reference. Scalability involving distributed ledgers refers to increasing the throughput of the system via distributed computing processes for use, service, or production across a range of features. Its applicability as a comparable point of reference is demonstrated via a 20th century and contemporary example ([cooperative] extension services).
The paper thus brings together language that is already familiar within the innovation literature (for example, Roger, 1962; Rogers \& Valentine, 1995), and adds new literature involving social machines and smartification (for example, Shadbolt et al., 2019, 2016, 2013; Smart \& Shadbolt, 2014, O'Hara, 2013), together with recent literature on DLTs (Nakamoto, 2008; Orcutt, 2015; Swan, 2015; Urgessa \& Vigna, 2015; Pilkington, 2016; Tapscott, 2016; Tapscotts, 2016, 2016a; UK Government Chief Scientific Adviser, 2016; Boucher, 2017; Calvo, 2017; Casey \& Vigna, 2017; Narayanan \& Clark, 2017; Tapscott, 2017; Werback, 2018; DuPoint, 2019; Zhu et al. 2019). The purpose of doing this is to raise awareness for researchers and technology entrepreneurs seeking to build or improve innovative infrastructure for social machines that will help smartify local and global economies. Both roles are important for economic development in laying a foundation for DLCs of the future. At the same time, both may benefit from comparing social machines and DLCs, in light of the scalable notion of "extension services", which may aid in conceptually approaching both how to innovate DLTs, as well as diffuse them in DLCs through digital extension activities that aim at smartification.

The conceptualization of DLCs as social machines allows us to formulate important interrelated questions. First, does such conceptualization help in our understanding of how to "smartify" an economy by using digital DLT-based tools, products and services? Second, how does considering the "smartification" process as happening through "digital extension services" help in answering the first question?

The paper considers "extension" as the driving source of "innovation diffusion" (Rogers, 1962). This simply means that innovation diffusion extends first from innovations themselves (Thiel \& Masters, 2014), which likewise extend from innovators, inventors, and entrepreneurs (Argabright et al., 2012). Innovation itself serves as an indicator in the process of digitally "smartifying" an economy, which requires concentrating digital resources and following the lead of innovative technology-led entrepreneurial startup ventures that strive to reach global, in addition to local, markets.

The paper traces a brief history of both social machines and DLTs through their similar time frames. A comparative literature review considers the two streams - by framing DLTs and social machines in their common context of striving towards "smartification". It then 


\section{Distributed Ledger Technologies and Social Machines: How to "Smartify" the Economy with Blockchain-based Digital Extension Services? Gregory Sandstrom}

applies some of the insights to a use case analysis focusing on the historical growth of "extension services" as an example ripe for comparison within the lenses of "digitalization" and "smartification", and thus to the growth of "digital extension services" in general.

\section{A Descriptive Analysis of Social Machines}

The initial meaning of "social machines" (1999) comes from computer scientist and inventor of the world wide web, Tim Berners-Lee, with Mark Fischetti, current editor of Scientific American, who stated: "Computers can help if we use them to create abstract social machines on the Web: processes in which the people do the creative work and the machine does the administration". From this, we see a conversation has grown up that involves human-machine interaction, human and social computing, as well as "collective intelligence", which means different things to people coming from different fields.

Berners-Lee and Fischetti (1999) identified "interconnected groups of people acting as if they shared a larger intuitive brain," in defining social machines on the world wide web. This was picked up more than a decade later by Shadbolt (2013), along with Smart et al. (2013), who provided an updated definition: "Social Machines are Web-based sociotechnical systems in which the human and technological elements play the role of participant machinery with respect to the mechanistic realisation of system level processes". Hooper et al. (2016) defined a "social machine" as "a socio-technical construct by which a human-machine collective achieves greater things than would be possible of the individual 'parts' working alone". Donath more recently widened the meaning of a social machine away from a mechanistic view, in speaking generally of "a communication medium and a setting for interactions, an electronic place to see and be seen" (2020). These definitions all relate to how digitalization impacts our daily activities, both mechanically and organically, as it enables new forms of "socialization" mediated in some cases by social machines.

A project named "SOCIAM" (https://sociam.org/) ran from 2012 to 2018, with funding by the U.K.'s Engineering and Physical Sciences Research Council. It linked three top universities in the U.K. to produce interdisciplinary web science research insights into social machines. In 2014, the project leaders pointed out that, "Social Machines are a characterization of technology-enabled social systems, seen as computational entities governed by both computational and social processes". The distinction between computational entities, and social systems/processes meanings was important to highlight regarding what is "technology-enabled" and what isn't. Following Berners-Lee and Frischetti's new term, earlier philosophers Deleuze and Guatarri (2004) noted that,

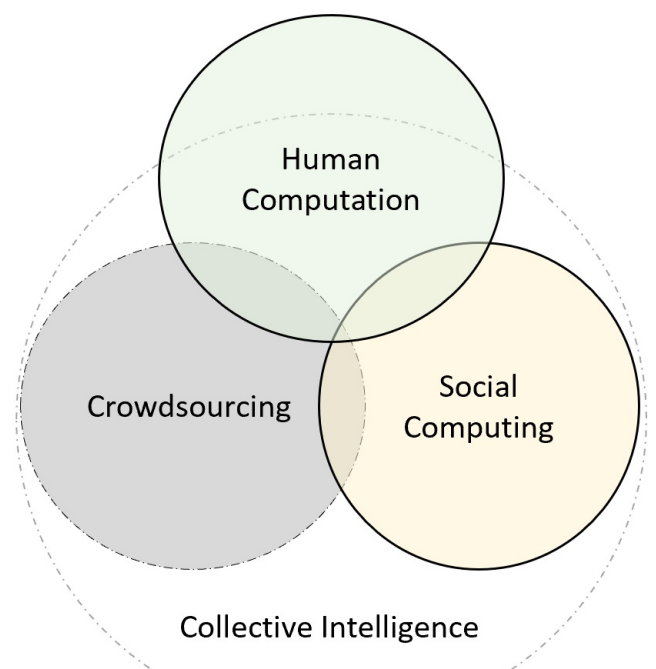

Figure 1. The intersection of human computation and social computing (adapted from Quinn \& Bederson [2011], and Romani \& Baranauskas [2013]) 


\section{Distributed Ledger Technologies and Social Machines: How to "Smartify" the Economy with Blockchain-based Digital Extension Services? Gregory Sandstrom}

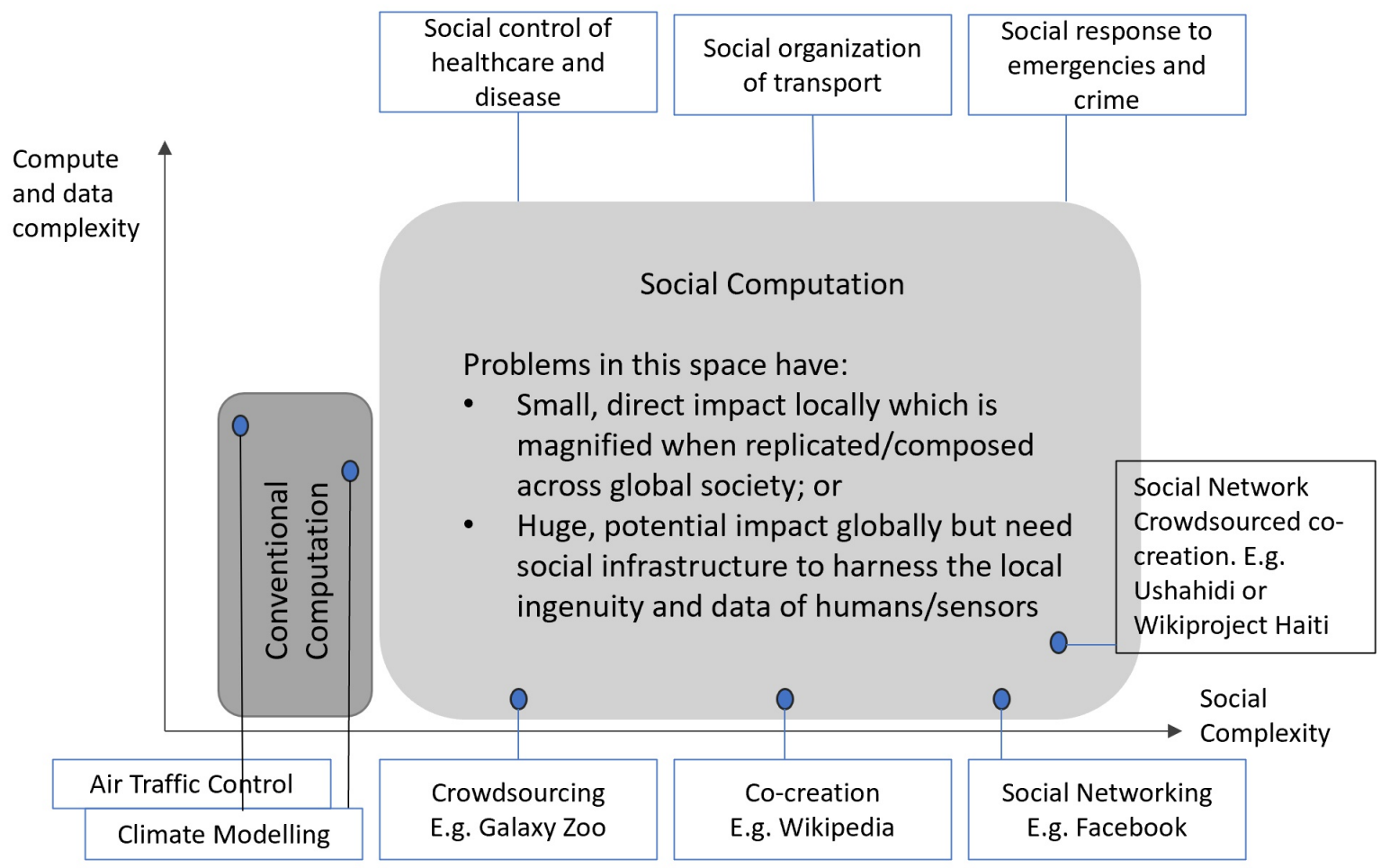

Figure 2. A space for social machines (adapted from O'Hara et al. 2013)

"The same machine can be both technical and social, but only when viewed from different perspectives: for example, the clock as a technical machine for measuring uniform time, and as a social machine for reproducing canonic hours and for assuring order in the city".

In a nutshell, what do social machines do? Crowdsourcing, collective intelligence, supply chain monitoring, file sharing, and citizen science, to name a few activities. What are examples of social machines? Wikipedia, Facebook, Twitter, Instagram, Duolingo, Zooniverse, Flickr, Patientslikeme, and Last.fm. How do people interface with social machines? Shadbolt et al. (2016) noted that, "[c]onsumer electronics in their current form of smartphones, wearables, and sensors, along with other devices yet to be envisioned, will power this next generation of systems, providing the key mechanisms that people will use to leverage a new type of social computational power. We refer to these as social machines". The trend in device innovation supports people making more and more frequent use of social machines with administration (automation, calculation, scheduling, etc.) done by computers, while creative work (networking, symbolic value-adding, trustbuilding, moral, ethical, and cultural aspects) is driven by (still-human) people.

According to Hendler and Mulvehill (2016) a social machine "represents the concept at the nexus of the increasing convergence of artificial intelligence, social networking, and human cognition". They believe that an "ability to easily communicate with others in our society regardless of time, geographical location, and social or economic status is the basis of the social machine" (Ibid). In short, they believe that social machines "enable humans and computers to work together as powerful teams" (Ibid). For some contemporary entrepreneurs who aren't on the cutting edges of web and information science, this may sound too futuristic. While for others, that time is already here, as we work out and discover new vocabularies for machine-human interaction on-line and with the Internet of Things.

Concerns remain, however, regarding dangers, warnings, and possible pitfalls arising from issues involving control over the machines that we are now creating. "The emergent Internet of Things and the 


\section{Distributed Ledger Technologies and Social Machines: How to "Smartify" the Economy with Blockchain-based Digital Extension Services? Gregory Sandstrom}

application of AI and blockchain technologies”, wrote Hall et al. (2016), "promises much in terms of smarter everything but we can also see a nightmare world of control by a network of machines and devices that we have little control over". This nightmare scenario may be considered when thinking of "societal machines" as tools of elite power over entire societies, rather than as "social machines" that facilitate digitally-mediated relationships and transactions between people in and across a range of societies. Hendler and Mulvehill (2016) instead took a more positive, constructive approach, saying, "we can continue to create and refine social machine technologies that can increasingly take advantage of the way that large numbers of people can network together to support real-world problems. With the help of other humans interacting with increasingly smart machines, we will be able to achieve many things that we cannot currently do". Similarly, Shadbolt et al. (2016) suggested that they "see a future where consumer electronic devices are not just personal accessories but rather the nodes that embed individuals within a variety of social machines".

In their book on social machines that resulted from the SOCIAM project, Shadbolt et al. (2019) stated that,
"[s]ocial machines should prompt neither optimism nor pessimism; they will enable new types of problem-solving and new types of mischief alike. To the academic community, our message is that social machines and CPSMs [cyber-physical social machines] deserve recognition and new types of interdisciplinary research. To policymakers, we say that social problems and the responses to them can productively be viewed through the social machine lens. To the technology industry, we argue that social machines are one of the chief social goods of platforms and other means of connecting people, and that the flourishing of sociality and communication within social machines should be a key part of the industry's contribution to societal welfare".

One of the challenges, as Hooper et al. note, is that "[m] ost if not all issues that social machines respond to have multiple stakeholders" (2016). This feature of social machines as involving multiple stakeholders is what makes the similarities most striking with blockchain DLCs, which also require multiple stakeholders to function. The reason for this is similar to what makes a "social machine" social, instead of just a "technical machine"; the technology is built in such a way that it requires a "community", meaning a big enough (mass) active user or member base for the logic of the system's benefits to become apparent.

\section{Comparing Distributed Ledger Communities (DLCs) and Social Machines}

One way to conceptualize "social machines" is through the recent rise of "blockchain" ("chain of blocks" in Nakamoto, 2008) DLTs, which do the accounting and some of the administration for DLCs (Sandstrom, 2017). These communities use informational (accounting) "ledgers" shared across a network of multiple (hundreds, often times thousands) of computers, according to protocols developed by "Satoshi Nakamoto" (Bitcoin), Hal Finney (Bitcoin), Gavin Andresen (Bitcoin), Vitalik Buterin (Ethereum), Gavin Wood (Ethereum, Polkadot), and many other software developers and engineers that have followed since.

Canadian business executive Don Tapscott (2016) suggested that, "the blockchain, the underlying technology [behind Bitcoin], is the biggest innovation in computer science- the idea of a distributed database where trust is established through mass collaboration and clever code rather than through a powerful institution that does the authentication and the settlement". To on-board people, one must therefore convince them that a DLC can deliver trust (Casey \& Vigna, 2017; Truong et al., 2018; Werbach, 2018) between human beings while enabling new or improved transactions involving value. The peer-to-peer (P2P) features of making direct transfers between members, and the possibility of anonymous (or pseudonymous) transactions, ratings, and exchanges, make DLTs suitable tools for a variety of industries and business interactions. DLTs thus lead to ledger communities (LCs) (Sandstrom, 2017) of people (users) who agree to the terms and conditions of the "Genesis Block" of that particular LC, and thus gain a measure of mutual trust in making transactions with others there.

These communities of mutually involved participant agents are the key drivers for people to adopt DLTs in "smarter city" environments (see Figure 3). All of the transactions take place, are recorded, and time-stamped between registered DLC members, who either transfer digital assets, tokens, points, credits, or information to 


\section{Distributed Ledger Technologies and Social Machines: How to "Smartify" the Economy with Blockchain-based Digital Extension Services? Gregory Sandstrom}

other members (or member "wallets") in the system. This enables "common pools of resources" (CPRs) and sense of trust based on participatory understanding to form around shared activities, purposes, transactions, and roles in a digital ecosystem.

Economist Elinor Ostrom described CPRs this way, outside of a DLT context:

\begin{abstract}
"We have learned that citizens do play an essential role in the governance of common pool resources and that efforts to turn over all of the responsibility for governing these resources to external experts are not likely to protect them in the long run. The complexity of the resources at local, regional, national, and global levels do require complex governance systems involving citizen input in diverse fashions" (In Helfrich, 2009).
\end{abstract}

With the need for a similarly diverse governance system, DLCs as social machines constitute online networks of trading, sharing, and value exchange that use a digital platform for activating fast and secure transactions and services enabled by DLTs (see Figure 4), sometimes involving CPRs. The incentive structure of DLCs, as Jose Luis Calvo suggests (2017), thus becomes quite attractive in that "participants of the system have more benefit working in favour of the system than against them [it]".

The emergence of DLT-based DLCs thus portend a massive re-classification and re-organisation of society, economics, and culture along new lines, networks, organizations, and communications channels. This will likely bring with it a different structure of power and governance than we have seen before, just as the internet changed the previous electric ecology in a profound way. This makes it humbling and precautionary to do origins and processes thinking about the complexity of DLTs at this early stage in their development. We need to look more closely into the "Genesis Block" (original first block) in every blockchain to find the "governing ideology" of each DLC, as this determines who its insiders and outsiders are, and how its rules and regulations govern, guide, assist, connect, and evaluate members.

It would be nearly impossible to understate the pent- up potential that this technology contains in terms of societal reconstruction, restrictions, inclusions, exclusions, and overall reorganisation along digital access and denial lines (what is a digital queue in DLTspace?). One need only recognise the power of "[a] cryptocurrency that's not based on nation-states" (Tapscott, 2016) to consider the foundationally disruptive potential of digital currencies as an alternative to nation-state backed "fiat currencies". The question now seems not to be if states will act to produce their own DLT-based platforms and systems, including potentially Central Bank digital currencies (CBDCs), but rather when, how, and in what order (see Estonia's XRoad platform). The halls of political and economic power around the world are now faced urgently with choices about what to do with DLTs, when applied broadly in/to economics, culture, language, politics, religion, education, and other areas (Swan, 2015; Urgessa \& Vigna, 2015; Tapscott, 2016; Tapscotts, 2016, 2016a; Casey \& Vigna, 2017; Tapscotts, 2017, 2017a). We ought to seek answers that draw out the ideas of academics, along with technologists, entrepreneurs, and community leaders so that we may "think things out before we put them out", a well-heeded McLuhan warning at obsessing in a Narcissus-like state with technology to our own detriment and loss of selfidentity.

DLTs seem aimed to eventually create societies that have new "communities of identity permission", wherein some people volunteer and can enter a ledger community, while other people do not wish to, or because of their already-made and indicated public preferences, are not allowed to. In other words, DLT social machines herald an era of "Are you in or are you out?", meaning "Do you hold certain principles of transacting in common with us according to your voluntarily published identity?", based on communitymarket membership and secure identity with "digital keys and signatures". Making decisions to be part of DLCs or not may become a significant feature of DLCdriven societies in the coming years.

Key issues involve "permissions" in a DLC, digital identity, access to digital assets, as well as voting rights, secure storage, information sharing opportunities, and other features. Thus, the question of whether a DLC is "permissionless" (one does not need permission to access it, or to interact with other members) or "permissioned" (permission is needed to access it, and 


\section{Distributed Ledger Technologies and Social Machines: How to "Smartify" the Economy with Blockchain-based Digital Extension Services? Gregory Sandstrom}

to interact with other members) is crucial for businesses and entrepreneurs to answer if they are thinking about building a DLT-backed product or service offering.

\section{Discussion: How to Smartify Social Machines with Digital Extension Services?}

According to the interpretation of "social machines" by Berners-Lee and Fischetti (1999), "The stage is set for an evolutionary growth of new social engines. The ability to create new forms of social process would be given to the world at large, and development would be rapid". While we can speak of an "evolutionary growth" when the topic is biological forms, in contrast, the growth of technological forms requires alternative language that specifically addresses and includes the "human factor". This is because social machines are "artificial" or "technological", rather than "natural" or "organic" entities. They thus do not "evolve" in the way biological organisms do. For this, an alternative language for change involving design and planning of digital platforms and ecosystems seems valuable, as social machines (or "engines") aim for both innovative simplicity and coherent design principles (Dorst, 2015).

The language of "extension" offers a direct channel to "agency", design, and planning in the study of economic development, being present in one way or another throughout economic theory. Each social machine has its own history that involves both economic and non-economic decisions and actions that extend from human agents and institutions. Thus, we can think about social machines as "extending" directly from community leadership, along with entrepreneurial activities, principles, innovations, and enterprises, both social and business in orientation. Ultimately DLT social machines extend to and from their users.

Social machines enabled by DLTs seen this way break new ground through the work of "digital extension agents" (compare with validators, endorsers, witnesses, node leaders, oracles). They may thus gradually or rapidly achieve a "network effect" by attracting smaller or larger communities of users. This reveals not only what (or who) the entrepreneurial activity extends from, but rather also and more importantly, what it extends to: a unique distributed market niche and an active, growing user community of networked individuals, yet without a single central source of control, just socially-accepted "rules of the game" in a DLC.

A social machine's smartification is partially demonstrated in its roll-out plan about how to scale. This means targeting "extensive growth", in addition to the "intensive growth" that comes already from possibilities present with the invention of "blockchain". Taking the combined extensive and intensive growth approach to DLTs, we can then consider, with greater foresight and accuracy than "evolutionary economics" allows, what impacts DLC social machines are likely to have on economic development, as well as how, where, and why they can be built.

Considerable work has been done applying "extension" thinking to a variety of technological innovations (McLuhan, 1964; Brey, 2000; Lawson, 2010; Steinert, 2015), and even to the consumer world (Belk, 1988, 2013). This provides entrepreneurs with an accessible language for describing both innovation conceptualization and product or service diffusion. Entrepreneur and venture capitalist Peter Thiel (with Blake Masters, 2014) most recently applied the notions of extensive and intensive growth specifically to innovation and development in Zero to One. The book showed that while both "intensive" and "extensive" thinking are needed for successful innovation diffusion, the core of innovative thinking is "intensive" in orientation. Innovations can be produced and potentially diffused (extended) from "one to infinity $(\infty)$ ", as a principle, yet the harder part in the task of generating meaningful disruptive change through innovation comes from making $\mathrm{a}(\mathrm{n}$ intensive) breakthrough from " 0 to 1 ", and thus the title of the book (see image below in Appendix).

Further good reasons exist to adopt "extension" language to address the rise of social machines given the importance for DLTs of navigating to scale globally. The historical diffusion of public cooperative extension services (mainly in education and agriculture) in multiple countries around the world, establishes them as arguably the single most influential and significant "social machine" to achieve mass scale created in world history, prior to the Internet. The role of extension services in the 1950s-60s "Green Revolution" through agricultural extension, and earlier with the university extension movement (see "distance education" or "lifelong learning") starting in the 1860s and 70s in the UK, 


\section{Distributed Ledger Technologies and Social Machines: How to "Smartify" the Economy with Blockchain-based Digital Extension Services? Gregory Sandstrom}

and a bit later in the USA (Chapin, 1894; Chapple 1896; Moulton 1897), provide significant cases in point. The examples of "extension" that bridge (academic) theory with practise (education and technology diffusion) may serve to help us now look more closely at what "digital extension services" might mean in the 21st century.

The question is still open how DLTs may be used to increasingly coordinate, grow, and serve globally online and connected users, given the current state of the technology. Without scaleup potential, DLT social machines face the risk of collapse and LC desertion, as has happened with many DLT projects already. This is where the addition of "extension" thinking and extension services becomes most appropriate, as a way of providing scale-ready thinking for DLT projects in quest of appropriate business and governance application.

The main challenge of scalability for DLCs is one of how to extend, that is, to experience and achieve scaleup. The question we can ask, following Thiel and Masters (2014), is: how to intentionally and with purpose build a DLT-backed DLC that attracts and enables " 1 to $n$ " growth of users and transaction to achieve a "network effect"? Deciding on how to create a DLC's extension services and network effect strategy thus enables DLTs to move from design and planning with theories into practise where active users are involved as participants in the decision-making process, or otherwise quickly to irrelevancy and to the community's quick collapse.

Digital extension services maintained over time provide examples of community generated and guaranteed leverage; a community "market voice". They draw on collective volunteer improvement though minimal provision of education and services that help local Users improve their earning, producing and basic living conditions or opportunities. DLCs similarly enable a process of to building new digital extension services upon already existing social machines, even while some principle of proportionality is needed in caution against over-extension.

With DLC social machines, the intensification of information matching and filtering opportunities across mutually "permissioned" datasets translates into finding ways to connect Members with others who can add values to the network. Some of these values are currently "invisible", according to the way the financial system is now configured. It will be up to new DLCs to make these values visible, beyond only financial applications via "cryptocurrencies" (Orcutt, 2015; UK Government Chief Scientific Adviser, 2016).

Looking at the origins of technology-driven companies and the discovery or achievement of innovations as examples of McLuhan's "extensions of man[kind]" helps us as to make sense of social machines using an inherently teleological term. The opportunity of taking on board this language of "intensive and extensive" thinking, where culture, media, technology, economy, and business meet, seems to be ripe for exploration regarding DLTs, given the planning and design that goes into business modelling and value proposition identification. Our team planning and design themselves take an "extension" thinking approach in community. It remains to be seen, however, if thinking about social machines using teleological language will help focus attention on some of the ethical, moral, economic, and political issues that currently face us as they rise to prominence, in ways that allow us to react to the pressing changes in technology happening around us.

Some of the key similarities and differences between social machines, DLCs and digital extension services are summarized in Table 1.

\section{Conclusion}

This paper involving conceptualization of DLCs as social machines aimed to address the following interrelated research questions: First, does such conceptualization help in our understanding of how to "smartify" an economy by using digital DLT-based tools, products and services? And second, how does considering the "smartification" process as happening through "digital extension services" help in answering the first question?

To the first question, based on the above, the answer appears to be "Yes". To the second, social machines in the form of DLCs can smartify economies through digital extension services via platforms that offer value-added benefits to multiple stakeholders and categories of users. This marks a continuation of common market mechanisms, with distributed thinking communityoriented features added into the digital ecosystems approach. The rise of DLCs thus appears crucial for business and management scholars, social scientists in general, and entrepreneurs to better understand, since 


\section{Distributed Ledger Technologies and Social Machines: How to "Smartify" the Economy with Blockchain-based Digital Extension Services? Gregory Sandstrom}

the growing usage of DLTs by DLCs will constitute new social and business markets, bringing along with them enterprise scale-up opportunities.

On the question of how to scale a distributed ledger system in a way to get a network effect, we can suggest that social machines both require and demonstrate digital extension. At least, it seems to make sense to speak about social machines as "extending" (rather than "evolving"), given how "extension thinking" has been invoked and applied in the past, as well as presently in several overlapping fields, including education, agriculture, technology, language, cognition, and even digital marketing. This paper thus

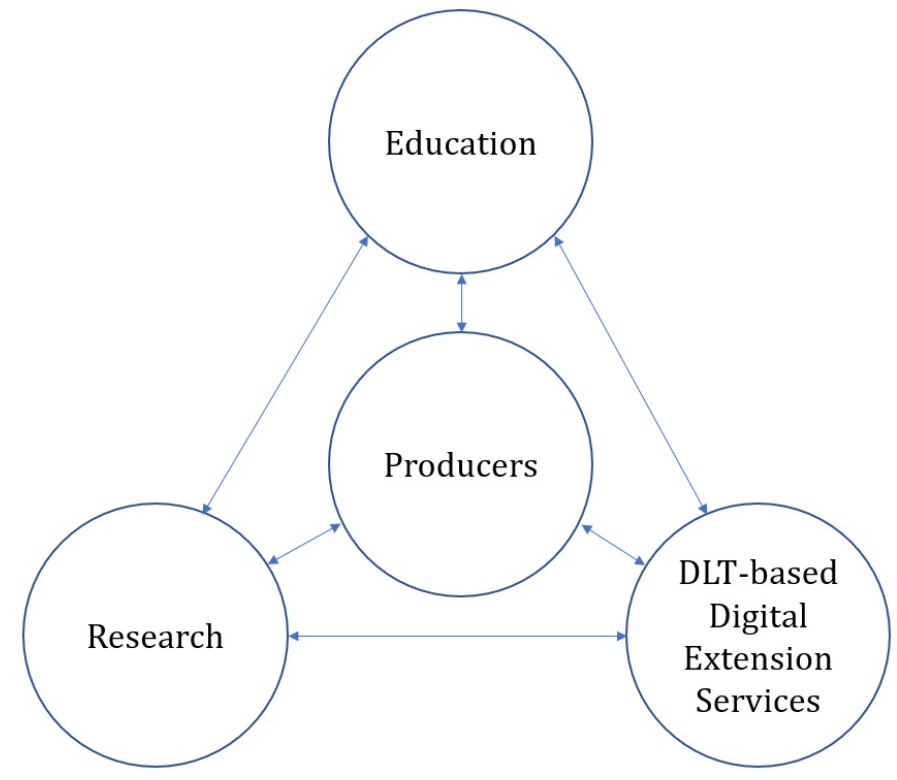

Figure 3. Agricultural Knowledge and Information Services Triangle Source: FAO and The World Bank 2000

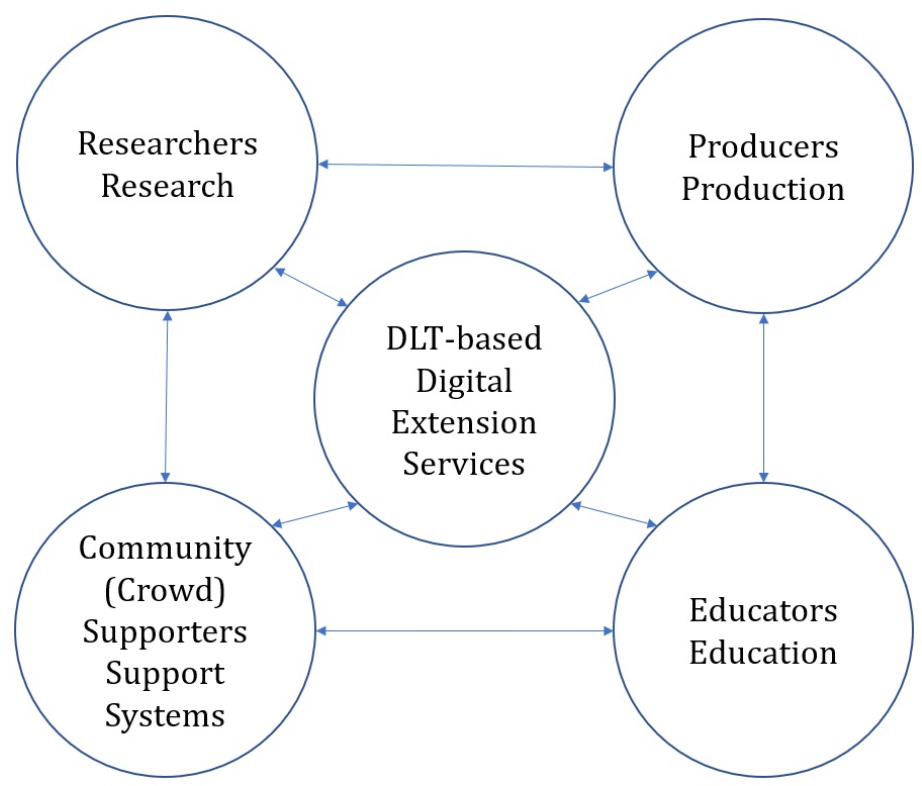

Figure 4. DLT-based digital extension services conceived as a social machine, which includes a "public ledger" (adapted and updated to add DLT backend, from Hunt et al., 2014) 


\section{Distributed Ledger Technologies and Social Machines: How to "Smartify" the Economy with Blockchain-based Digital Extension Services? Gregory Sandstrom}

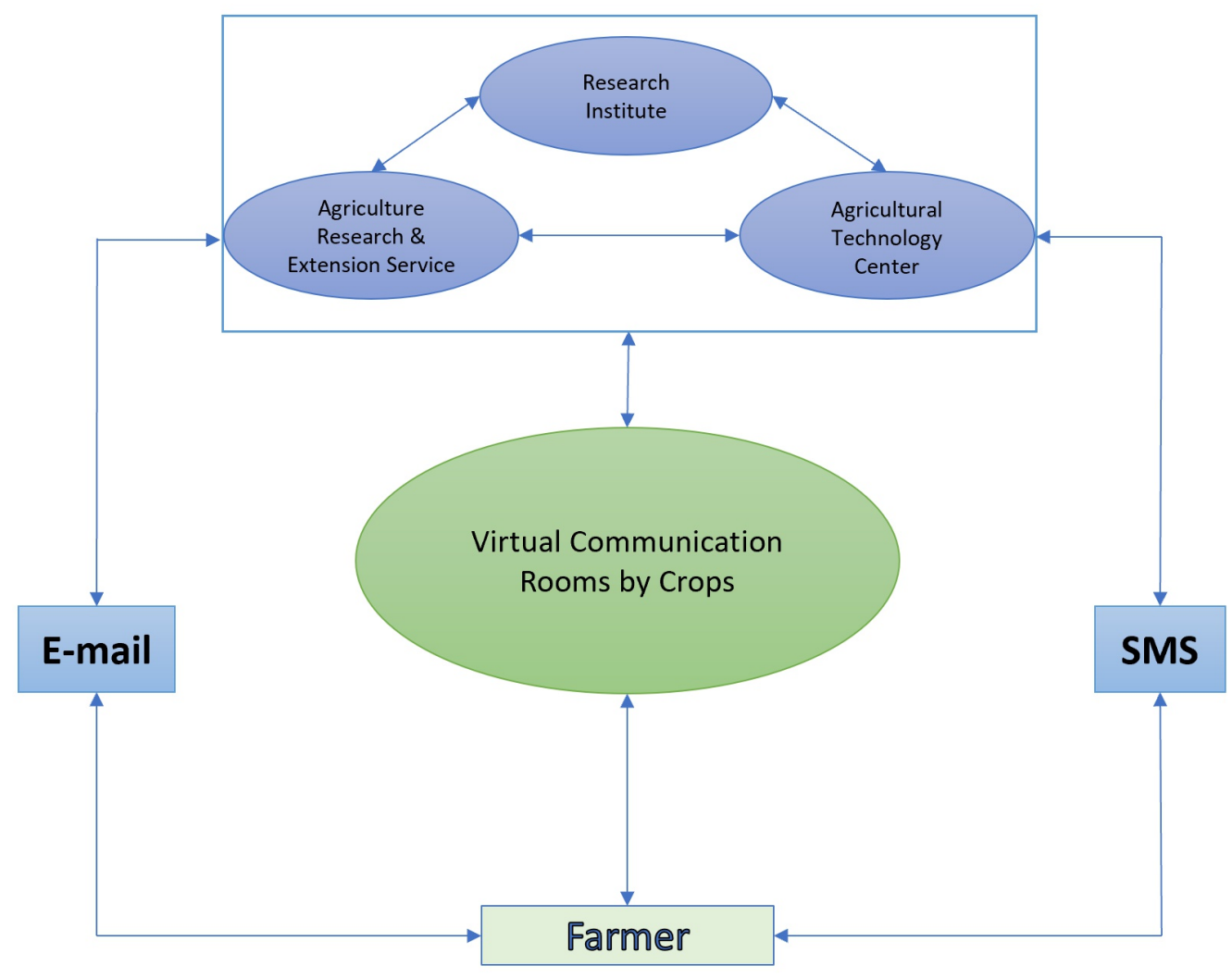

Figure 5. Extension services in a Digital Communications Ecosystem (adapted from Singh, 2006)

suggested a historical comparison to consider and explore further involving the growth of the agricultural extension movement (Roling, 1988), and university extension movements of the 19th and 20th centuries (Chapin 1894; Chapple 1896; Moulton 1897; Bittner, 1920; Lawrie, 2014), as models for the kinds of "scale change" and structural realignment that we are facing in some ways today with the digitization of economics. Today we are faced with a simple, but difficult question: How are our social machines going to be built and steered, and by whom; individuals or communities? Broader issues of DLC governance, accessibility, financial inclusion, and economic development thus continue to frame the background for this research topic.

In short, if a team builds a digital platform using DLTs, then if that platform gains attention and active user traction, they have effectively also built a "social machine". The rise of social machines should thus be more widely known in the entrepreneurial community since building them may constitute foundational innovation if a social machine works and its model is replicated by other startups. Further research can be conducted into digital (or digitizing) extension services as ways of scaling social machines based on new and established practises and strategies. A required focus on "social enterprise", not necessarily to replace, but rather to function alongside of the "corporate enterprise" or "business enterprise" of blockchains, seems to come as part of the required conversation, given the "distributed" or "decentralized" character of DLT-backed enterprises.

The paper did not address issues involving the management and governance (that is, politics and policies) of DLCs. Rather, it offered a way to think about DLCs as "social machines" constructively towards building better ones in the future, according to the categories of "smartification", with the assumption that management and governance strategies will be included in the process. It did not make a case for whether to regulate algorithms in social machines or even how this could be done in a "smart" or "smarter" way. How "smart" the "smartness" is supposed to be wasn't the 


\section{Distributed Ledger Technologies and Social Machines: How to "Smartify" the Economy with Blockchain-based Digital Extension Services? Gregory Sandstrom}

Table 1. Similarities and differences of social machines, distributed ledger communities and digital extension services

\begin{tabular}{|c|c|c|c|}
\hline Feature & Social Machines & $\begin{array}{c}\text { Distributed Ledger } \\
\text { Communities }\end{array}$ & $\begin{array}{c}\text { Digital Extension } \\
\text { Services }\end{array}$ \\
\hline Digitalization & Yes & Yes & Yes \\
\hline $\begin{array}{c}\text { Scale: Mass } \\
\text { Audience aim }\end{array}$ & Yes & Yes & Yes \\
\hline Automation & Sometimes & Yes & Sometimes \\
\hline $\begin{array}{c}\text { Multiple } \\
\text { Stakeholders }\end{array}$ & Yes & Yes & Yes \\
\hline $\begin{array}{c}\text { Combined } \\
\text { Computational \& } \\
\text { Social Elements }\end{array}$ & Yes & Yes & Yes \\
\hline $\begin{array}{c}\text { Interactive } \\
\text { Applications }\end{array}$ & Yes & Yes & Yes \\
\hline Web 3.0 & Yes & Yes & Yes \\
\hline Timestamping & Sometimes & Yes & Sometimes \\
\hline Encryption & Sometimes & Sometimes & Possible Option \\
\hline Smart Contracts & Possible option & Yes & Yes \\
\hline Big Data & Oftentimes & & \\
\hline
\end{tabular}

main point of the article. It served instead as a conceptual paper to introduce a "frame innovation" (Dorst, 2015) for making sense of the incoming effects of social machines, through comparison with DLCs and extension services in areas relevant to entrepreneurial and economic development.

In short, the paper should appeal to entrepreneurial and business opportunities now arising via digital platforms based on DLTs, rather that getting philosophical about social machines, and what risks and rewards they (may) pose to humanity. It looked at how to make sense of economic development today when considering "distributed ledger communities" as "social machines" that can be "extended" through various digital tools, products, and services. To do this, it provided insight into the impacts these new technologies will have on how we create and store data, buy and sell electronic assets, as well as organize, manage, transact, and transfer information peer-topeer.

The paper offered a sociological perspective on smart(er) digital economies to open a new conversation that brings together several over-lapping languages and socio-technical contexts. Social machines and DLTs appear set to be among the most disruptive innovations for societies around the world since the computer and internet. They provide digital tools, processes, procedures, and governance options via local and regional, along with global "extension" agents to reach masses as well as targeted niches of online participants. Innovative DLCs must there involve administrative and informational foresight about how to use the current and new technological tools to engage knowledges that come from centres, peripheries, and everywhere in between. The arrival of DLTs fundamentally changes the research landscape for social and applied scientists and innovators by enabling new "testing" grounds with volunteer users who can now finally be protected in more secure ways from institutional exploitation with "self-sovereign" digital identities.

The topics highlighted in this paper raise significant ethical issues. The use of real-time updated, dynamic public/private hybrid databases based on voluntary data sharing in using "mechanisms" available in today's newly forming DLCs is significant. The data collected from members can be used to create a reallife experimental (educational, marketing, or other) laboratory involving actual decisions that people make at micro-, mesa-, and potentially larger society-wide macro- levels. We have a lot of work still in front of us to figure out how to do this the right way, which requires "smarter" distributed thinking that has not yet been cached out or discussed. 


\section{Distributed Ledger Technologies and Social Machines: How to "Smartify" the Economy with Blockchain-based Digital Extension Services? Gregory Sandstrom}

\section{References}

Argabright, K,. McGuire, J., \& King, J. 2012. Extension Through a New Lens: Creativity and Innovation Now and for the Future. Journal of Extension, (50)2.

Belk, R.W. 2013. Extended Self in a Digital World. Journal of Consumer Research, 40(3): 477-500. DOI: https://doi.org/10.1086/671052

Belk, R.W. 1988. Possessions and the Extended Self. Journal of Consumer Research, 15: 139-168.

DOI: https://doi.org/10.1086/209154

Berners-Lee, T., \& Fischetti, M. 1999. Weaving the Web: The Original Design and Ultimate Destiny of the World Wide Web. New York: Harper.

Berners-Lee, T., Hall, W., Hendler, J.A., O'Hara, K., Shadbolt, N., \& Weitzner, D.J. 2006. A Framework for Web Science. Foundations and Trends in Web Science, 1(1): 1-130.

DOI: https://doi.org/10.1561/9781933019802

Bheemaiah, K. 2017. The Blockchain Alternative: Rethinking Macroeconomic Policy and Economic Theory. Paris: Apress.

Bittner, W.S. 1920. The University Extension Movement. Washington: Government Printing Office.

Black, A.W. 2000. Extension Theory and Practice: a review. Australian Journal of Experimental Agriculture, 40(4): 493-502.

DOI: https://doi.org/10.1071/ea99083

Boserup, E. [1965] 2005. The Conditions of Agricultural Growth: the economics of agrarian change under population pressure. New Brunswick, New Jersey: Aldine Transaction.

Boucher, P. 2017. How Blockchain Technology Could Change Our Lives. European Parliamentary Research Service.

DOI:

http://www.europarl.europa.eu/thinktank/en/docu ment.html?reference=EPRS_IDA(2017)581948

Brey, P. 2000. Technology as Extension of Human Faculties. Metaphysics, Epistemology, and Technology. Research in Philosophy and Technology, 19. Ed. C. Mitcham. London: Elsevier/JAI Press.

Buregio, V., Meira, S., \& Rosa, N. 2013. Social Machines: A Unified Paradigm to Describe Social Web-Oriented Systems. Association for Computing Machinery: 885890.

DOI: https://doi.org/10.1145/2487788.2488074

Calvo, J.L. 2017. Why is Blockchain so difficult to explain? Medium.

https://medium.com/technology-changing-theworld-we-know/why-is-blockchain-so-difficult-toexplain-f3308aedc0b6\#.fgos7hkxp

Canny, J., \& Eric P. 2000. Tele-Embodiment and Shattered Presence: Reconstructing the Body for Online Interaction. In The Robot in the Garden: Telerobotics and Telepistemology on the Internet. Ed.
Ken Goldberg, MIT Press.

Casacuberta, D. 2018. Social Machines and the Internet: what went wrong? BiD: textos universitaris de biblioteconomia $i$ documentació, núm. 41 (desembre). Accessed

http://bid.ub.edu/en/41/casacuberta.htm DOI: http://dx.doi.org/10.1344/BiD2018.41.8

Casey, M., \& Vigna, P. 2017. The Truth Machine: The Blockchain and the Future of Everything. St. Martin's Press.

Castronova, E. 2007. Exodus to the Virtual World. Palgrave Macmillan.

Chapin, A.J. 1894. University Extension. Mary Kavanaugh Oldham Eagle, ed. The Congress of Women: Held in the Woman's Building, World's Columbian Exposition, Chicago, U.S.A., 1893. Chicago: Monarch Book Company: 393-397.

http://digital.library.upenn.edu/women/eagle/cong ress/chapin.html

Chapple, W.A. 1896. Extension of Technology in Education. Inaugural Address Delivered at the Women's Institute, Wellington, in The Citizen, Wellington: Edwards, Russell \& Co.

De Roure, D., Hooper, C., Meredith-Lobay, M., Page, K., Tarte, S., Cruickshank, D., \& De Roure, C. 2013. Observing Social Machines, Part 1: What to observe? In: WWW2013 Workshop: The Theory \& Practice of Social Machines. Rio de Janeiro, Brazil.

DOI: https://doi.org/10.1145/2487788.2488077

Deleuze, G., \& Felix G. [1972] 2004. Anti-Oedipus, Capitalismus and Schizophrenia. Minneapolis, University of Minnesota Press.

Donath, J. 2020. The Social Machine: Designs for Living Online. MIT Press on COVID-19. https: / / covid-19.mitpress.mit.edu/social-machine

Dorst, K. 2015. Frame Innovation: Create New Thinking by Design. MIT Press.

DuPoint, Q. 2019. Cryptocurrencies and Blockchains. Polity.

Hall, W., Hendler, J., \& Staab, S. 2016. Web Science Manifesto.

webscience.org/wp-

content/uploads/sites/117/2016/11/WebScienceManifesto-final.pdf

Helfrich, S. (ed.). 2009. Genes, Bytes and Emissions: To Whom Does the World Belong? Heinrich Boll Foundation

Hendler, J., \& Berners-Lee, T. 2010. From the Semantic Web to Social Machines: A research challenge for AI on the World Wide Web. Artificial Intelligence, 174(2): 156-161.

DOI: https://doi.org/10.1016/j.artint.2009.11.010

Hendler, J., \& Mulvehill, A. 2016. Social Machines: The Coming Collision of Artificial Intelligence, Social Networking, and Humanity. Apress Publishers. 


\section{Distributed Ledger Technologies and Social Machines: How to "smartify" the economy with blockchain-based digital extension services? Gregory Sandstrom}

Hooper, C.J., Bailey, B., Glaser, H., \& Hendler, J. 2016. Social Machines in Practice: solutions, stakeholders and scopes. In: Proceedings of the 8th ACM Conference on Web Science: 156-160.

Hunt, W., Birch, C., Vanclay, F., Coutts, J. 2014. Recommendations arising from an analysis of changes to the Australian agricultural research, development and extension system. Food Policy, 44: 129-141.

Jones, M., \& Kondylis, F. 2016. Your Feedback Matters, to You: Evidence from Extension Services. World Bank Development Economics Research Group.

Lawson, C. 2010. Technology and the Extension of Human Capabilities. Journal for the Theory of Social Behaviour, 40(2): 207-223.

DOI:

5914.2009.00428.x

Lee, R., \& Wellman, B. 2012. Networked: The New Social Operating System. Boston, USA: MIT Press.

Ling, R., \& Wong, A. 2011. Mobile Interactions as Social Machines: Poor Urban Youth at Play in Bangladesh. In: From Social Butterfly to Engaged Citizen, ed. Marcus Forth. Cambridge: MIT Press.

McLuhan, M., \& McLuhan, E. 1988. Laws of Media: The new science. Toronto: University of Toronto Press.

McLuhan, M. 1964. Understanding Media: The Extensions of Man. Toronto: Signet.

MIT Media, Laboratory for Social Machines. https://www.media.mit.edu/groups/socialmachines/overview/

Moulton, R.G. 1897. The University Extension Movement. London and Derby: Bemrose \& Sons.

Nakamoto, S. 2008. Bitcoin: A Peer-to-Peer Electronic Cash System. Unpublished paper.

Available at: https://bitcoin.org/bitcoin.pdf.

Narayanan, A., \& Clark, J. 2017. Bitcoin's Academic Pedigree: The concept of cryptocurrencies is built from forgotten ideas in research literature. ACMQueue.

https://queue.acm.org/detail.cfm?id=3136559

O'Hara, K., Contractor, N.S., Hall, W., Hendler, J.A., \& Shadbolt, N. 2013. Web Science: understanding the emergence of macro-level features on the World Wide Web. Foundations and Trends in Web Science, 4: 103-267.

O'Hara, K. 2014. Social machines as an Approach to Group Privacy. In: Group Privacy? New Challenges of Data Technologies, Amsterdam, Netherlands.

Orcutt, M. 2015. Why Bitcoin Could Be Much More Than a Currency. MIT Technology Review.

https://www.technologyreview.com/s/537246/whybitcoin-could-be-much-more-than-a-currency/
Pilkington, M. 2016. Blockchain Technology: Principles and Applications. Research Handbook on Digital Transformations, edited by Olleros., F.X., \& Zhegu, M. Edward Elgar.

Principles for Digital Development 2018. How to Build a Scalable Pilot Program for Digitally Enabled Extension Services.

https://digitalprinciples.org/resource/how-to-builda-scalable-pilot-program-for-digitally-enabledextension-services/

Quinn, A.J., \& Bederson, B.B. 2011. Human Computation: a survey and taxonomy of a growing field. In: $\mathrm{CHI}^{\prime} 2011$, ACM.

Rogers, E.M. 1962. Diffusion of Innovations. New York: Free Press of Glencoe.

Rogers, E. \& Thomas V. 1995. The Origins and Development of the Diffusion of Innovations Paradigm as an Example of Scientific Growth. Science Communication. 16(3): 242-273.

DOI: https://doi.org/10.1177/1075547095016003002

Röling, N.G., \& Engel, P.G.H. 1991. IT from a knowledge system perspective: concepts and issues. Paper presented at: The European Seminar on Knowledge Management and Information Technology, Wageningen.

Röling, N. 1988. Extension Science: Information Systems in Agricultural Development. Cambridge University Press.

Ryan, B., \& Gross, N.C. 1943. The Diffusion of Hybrid Seed Corn in Two Iowa Communities. Rural Sociology, 8: 15-24.

Sandstrom, G. 2017. Who Would Live in a Blockchain Society? The Rise of Cryptographically-Enabled Ledger Communities. Social Epistemology Review and Reply Collective, (6)5: 27-41.

DOI: http://wp.me/p1Bfg0-3A8

Schuh, G., Zeller, V., Hicking, J., \& Bernardy, A. 2019. Introducing a Methodology for Smartification of Products in Manufacturing Industry. Procedia CIRP, 81:228-233.

https://doi.org/10.1016/j.procir.2019.03.040

Shadbolt, N.R. 2013. Knowledge Acquisition and the Rise of Social Machines. International Journal of Human-Computer Studies, 71(2): 200-205.

DOI: https://doi.org/10.1016/j.ijhcs.2012.10.008

Shadbolt, N., O'Hara, K., De Roure, D., \& Hall, W. 2019. The Theory and Practice of Social Machines. Springer.

Shadbolt, N., Van Kleek, M., \& Binns, R. 2016. The Rise of Social Machines: The development of a human/digital ecosystem. IEEE Consumer Electronics Magazine, 5(2): 106-111.

DOI: 10.1109/MCE.2016.2516179 


\section{Distributed Ledger Technologies and Social Machines: How to "smartify" the economy with blockchain-based digital extension services? Gregory Sandstrom}

Shadbolt, N., Smith, D.A., Simperl, E., Kleek, M.V., \& Yang, Y. 2013. Towards a Classification Framework for Social Machines. In: Proceedings of the SOCM2013: The Theory and Practice of Social Machines, Rio de Janeiro, Brazil, 13-17 May 2013: 1-7. DOI: https://doi.org/10.1145/2487788.2488078

Shadbolt, N.R. 2013. Knowledge Acquisition and the Rise of Social Machines. International Journal of Human-Computer Studies, 71(2): 200-205.

DOI: https://doi.org/10.1016/j.ijhcs.2012.10.008

Shadbolt, N., \& Berners-Lee, T. 2008. Web Science Emerges. Scientific American, 299(4): 76-81.

DOI:

https://doi.org/10.1038/scientificamerican1008-76

Singh, S. 2006. Selected Success Stories on Agricultural Information Systems. Asia-Pacific Association of Agricultural Research Institutions, FAO Regional Office for Asia and the Pacific.

Smart, P.R., \& Shadbolt, N.R. 2014. Social Machines. In: Khosrow-Pour, Mehdi (ed.) Encyclopedia of Information Science and Technology. Hershey, Pennsylvania, USA, IGI Global: 6855-6862.

Smart, P.R. 2012. The Web-Extended Mind. In: Special Issue: Philosophy of the Web, Metaphilosophy, 43(4): 426-445.

DOI:

9973.2012.01756.x

https://doi.org/10.1111/j.1467-

Smart, P., Simperl, E., \& Shadbolt, N. 2014. A Taxonomic Framework for Social Machines. Social Collective Intelligence, 51-85.

DOI: https://doi.org/10.1007/978-3-319-08681-1_3

Steinert, S. 2015. Taking Stock of Extension Theory of Technology. Philosophy and Technology, 29(1): 61-78. DOI: https://doi.org/10.1007/s13347-014-0186-3

Swan, M. 2015. Blockchain: Blueprint for a New Economy. Sebastopol: CA: O'Reilly.

Tapscott, D. 2016. How Blockchains Could Change the World. McKinsey.

http://www.mckinsey.com/industries/hightech/our-insights/how-blockchains-could-changethe-world

Tapscott, D., \& Tapscott, A. 2017a. Realizing the Potential of Blockchain: A Multistakeholder Approach to the Stewardship of Blockchain and Cryptocurrencies. World Economic Forum. https://www.weforum.org/whitepapers/realizingthe-potential-of-blockchain

Tapscott, D \& Tapscott, A. 2017. The Blockchain Corridor: Building an Innovation Economy in the 2nd Era of the Internet. The Tapscott Group.

Tapscott, D., \& Tapscott, A. 2016a. Blockchain Revolution: how the technology behind bitcoin is changing money, business, and the world. Portfolio.
Tapscott, D., \& Tapscott, A. 2016. The Impact of the Blockchain Goes Beyond Financial Services. Harvard Business Review.

Available at: https://hbr.org/2016/05/the-impact-ofthe-blockchain-goes-beyond-financial-services

Thiel, P., \& Masters, B. 2014. Zero to One: notes on startups, or how to build the future. London, Virgin Books.

Truong, B.B., Um, W., Zhou, B., \& Lee M.G. 2018. Strengthening the Blockchain-based Internet of Value with Trust. IEEE.

DOI: https://doi.org/10.1109/icc.2018.8423014

UK Government Chief Scientific Adviser. 2016. Distributed Ledger Technology: beyond block chain. Government Office for Science.

Urgessa, G.S., \& Vigna, P. 2015. The Age of Cryptocurrency: How Bitcoin and Digital Money are Challenging the Global Economic Order. St. Martin's Press.

Wellman, B. 2001. The Rise of Networked Individualism. In: Community Informatics, edited by Leigh Keeble and Brian Loader. London: Routledge: 17-42.

Werbach, K. 2018. The Blockchain and the New Architecture of Trust. MIT Press.

Zhu, Q., Loke, S.W., Trujillo-Rasua, R., Jiang, F., \& Xiang, Y. 2019. Applications of Distributed Ledger Technologies to the Internet of Things: A Survey. ACM Computer Survey. 52, 6, Article 120 (November). DOI: https://doi.org/10.1145/3359982 


\title{
Distributed Ledger Technologies and Social Machines: How to "smartify" the economy with blockchain-based digital extension services? Gregory Sandstrom
}

\begin{abstract}
About the Author
Gregory Sandstrom is Managing Editor of the TIM Review. He is a former Associate Professor of Mass Media and Communications at the European Humanities University (2012-2017), and Affiliated Associate Professor at the Social Innovations Laboratory, Mykolas Romeris University (2016-2017) in Vilnius, Lithuania. His PhD is from St. Petersburg State University and the Sociological Institute of the Russian Academy of Sciences. He interned at the S.I. Vavilov Institute for the History of Science and Technology, St. Petersburg, sector on Sociology of Science (2010). He was a Postdoctoral Research Fellow at the Lithuanian Science Council (20132015), for which he conducted research visits to the Copernican Centre for Interdisciplinary Studies (Krakow), the University of Edinburgh's Extended Knowledge Project, Cambridge University's History and Philosophy of Science Department, and Virginia State University's Science and Technology Studies program. He worked for the Bard College Institute for Writing and Thinking, leading student and faculty language and communications workshops, most recently $(2013,2014,2017)$ in Yangon, Myanmar. His current research interests are distributed ledger technology (blockchain) systems and digital extension services.
\end{abstract}

Citation: Sandstrom, G. 2021. Distributed Ledger Technologies and Social Machines: How to "smartify" the economy with blockchainbased digital extension services? Technology Innovation Management Review, 11(6): 42-57.

http://doi.org/10.22215/timreview/1449

Keywords: Digital economy, social machines, smartification, web science, artificial intelligence, Internet of Things, digital platform, blockchain, distributed ledger technology, ledger community, innovation diffusion, extension thinking, extension services, economic development 


\section{Distributed Ledger Technologies and Social Machines: How to "smartify" the economy with blockchain-based digital extension services? Gregory Sandstrom}

\section{Appendix}

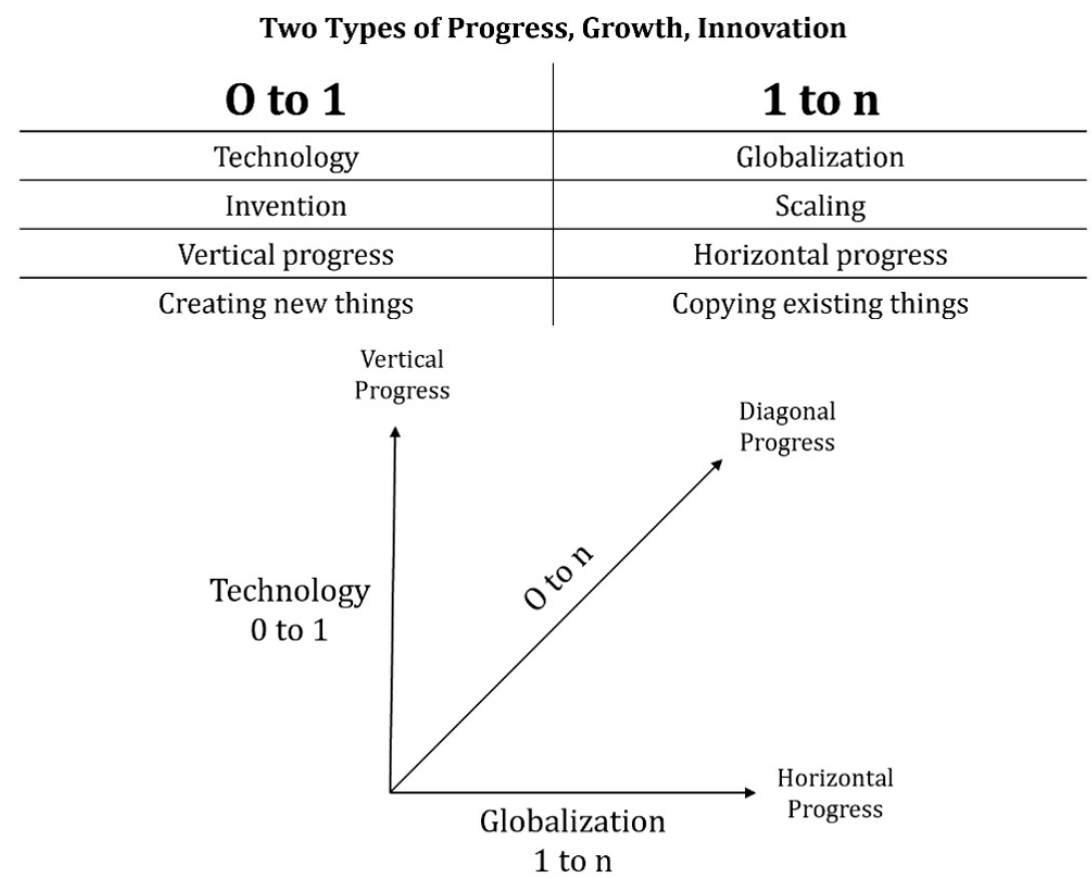

Figure 6. Intensive (" 0 to 1 ") and Extensive ("1 to n") thinking about progress, growth, development \& innovation.

Source: Image modified from Thiel \& Masters, 2014. This diagram adds to Thiel \& Masters with "0 to n" diagonal progress. 